\title{
English as a Medium of Instruction in Learning Professional Skills for Engineers
}

\begin{abstract}
Adrián Peñate Sánchez
adrian.penate@ulpgc.es

Universidad de las Palmas de Gran Canaria, Spain

Peñate Sánchez, A. (2021). English as a Medium of Instruction in Learning Professional Skills for Engineers. Language Value, 14(2), 24-44. Universitat Jaume I ePress: Castelló, Spain. http://www.languagevalue.uji.es.

December 2021

DOI: $10.6035 /$ languagev. 5841

ISSN 1989-7103
\end{abstract}

\section{ABSTRACT}

In this article, we reflect on the variables to be considered when teaching in English a subject of the bachelor's degree of Computer Engineering: "Learning Professional Skills for Engineers". In order to make this study, we start from an analysis of the recent history of teaching in English at university level and the institutional context in which it happens. Three research questions are posed, with the intent to check what minimum conditions must be met to be able to teach this subject in English. The results lead us to conclude that the option of English as a Medium of Instruction (EMI) is not the appropriate one, taking into account both the linguistic and didactic training of the teaching staff and the language accreditation of the students. However, it is feasible to opt for the Integrating Content and Language in Higher Education (ICLHE) option.

Keywords: EMI (English as a Medium of Instruction); ICLHE (Content and Language in Higher Education); Computer Engineering; Linguistic Level 


\section{INTRODUCTION}

The title of this article focuses on the concept of English as a Medium of Instruction (EMI). Therefore, it is necessary to analyze two fundamental aspects: firstly, the way in which EMI has been incorporated in different European universities, and secondly, the legislation or recommendations developed for this purpose in Europe, Spain and the Canary Islands.

Based on this reflection, three research questions are posed to verify, in the first place, what response has been given to the Canary Islands government's requirement to teach five percent of the subjects in English. Next, we check whether the minimum conditions required to teach using EMI are met at this university. And finally, we intend to define the fundamental elements that must be taken into account when designing the teaching project of the subject Learning Professional Skills for Engineers. '

\section{ENGLISH AS A MEDIUM OF INSTRUCTION}

Especially in the Nordic countries (Denmark, Finland, Norway and Sweden) EMI education has become particularly relevant since the end of the 20th century, with an even greater strength at the beginning of this century (Berg et al., 2001). The main reasons that have led these countries to take this decision have been three (Airey, 2004, p. 1): "internationalisation, preparing students for an academic world dominated by English and competitive advantages on the job market". And to these three reasons are added others that refer to the social context of these countries: their small populations and limited internal markets (Airey et al., 2015, p. 9). This trend towards an increase in the implementation of EMI teaching has experienced an exponential growth especially in Masters courses (Coleman, 2006, p. 6).

It could be argued that this is a top-down model in which decisions are made by the academic authorities of each university or even higher levels of local government. At the same time, we could also define that there is another model that we will call bottomup. These are universities that make decisions based on the bilingual teaching model that students have had at lower, non-university levels. This is the case of some 
universities in other parts of Europe, such as some universities in the Basque Country in Spain (Doiz et al., 2011)

The adoption of this type of teaching is not without debate and doubt, doubts that refer to the level of learning of the specific contents of the different subjects, and also to the possible loss in the learning of the some technical terms in the mother tongue.

\section{II.1. The effects on the learning of the content subjects}

When teaching different subjects, the first question we all ask ourselves refers to the consequences it has on the learning process of the subject matter. Although it might seem that in the Nordic countries there is no need to raise this point of view, because of the high level of English among students, we do find this issue in the debate in countries such as Sweden. However, "little research has been carried out at university level into the effects of teaching through the medium of English. (Airey, 2004, p. 7; Airey et al., 2015, p. 16)

In order to try to deepen the effects that its teaching in English has on the learning of a subject, numerous studies have been carried out. The experimental study by Airey and Linder (2006) examines the effect on university level learning of Physics in two teaching contexts: in English and in Swedish. The study was conducted with 22 students who were given a series of lessons in English and lessons in Swedish. Data were collected using semi-structured interviews in which the learners first described their experience in both types of class. In this first phase, the students did not see any difference in their experience as students in the two types of classes. Later, students were introduced to some video segments taken in the classes. With this process of stimulated recall, the students' opinions were again solicited. The results obtained from the second interviews and the video recordings of the classes are summarized in the following quote:

"When taught in English the students in our study asked and answered fewer questions and reported being less able to follow the lecture and take notes at the same time. Students employed a number of strategies to meet the problems by asking questions after the lecture, changing their study habits so that they no longer took notes in class, reading sections of work before class or - in the worst case - by simply using the lecture 
for mechanical note taking and then (perhaps?) putting in more work to make sense of these notes later." (Airey \& Linder, 2006, p. 558)

\section{II.2. The effects on the mother tongue}

The implementation of university education in English is considered by some as a way of relegating the mother tongue to a second level, leaving English to assume the higher and more scientific role. This leads Coleman (2006) to predict that "ultimately, the world will become diglossic, with one language for local communication, culture and expression of identity, and another - English - for wider and more formal communication, especially in writing." (p. 11).

This is the fear expressed by the Nordic countries for having minority mother tongues (Airey et al. 2015, p.10). This has led some universities, that are leaders in the mass introduction of English in these countries, to reformulate their educational offerings. Thus, "the recent changes introduced at Uppsala University would appear to be a laudable attempt to shift the balance back towards Swedish, and deal with perceived shortcomings in the Swedish scientific language of students." (Airey, 2004, p. 8)

\section{THE INSTITUTIONAL CONTEXT}

In this section, we will analyse the decisions related to the Linguistic Policy that have been taken in Europe, Spain and the Canary Islands.

\section{III.1. The European perspective}

Since the Bologna Declaration in 1999, the need for European universities to be attractive and competitive at world level has been defined. This approach implies the need, among many other factors, to increase and improve the linguistic competence of students and teachers in order to access the internationalization of our universities.

In subsequent meetings (Lisbon 2000, Barcelona 2002, Bergen 2005) this idea took shape, which led to the approval in 2007 of the following document: European Higher Education in a Global Setting. A Strategy for the External Dimension of the Bologna 
Process (Norwegian Ministry of Education and Research, 2007). Although the topic under discussion here is not explicitly mentioned in this document, it is specified in the annex (Elements for possible future actions): the need of foreign language learning (2007, p. 13)

In 2013, the European Commission sets out a series of key priorities in the document European Higher Education in the World (2013). One of these priorities is international mobility. But since only a minority benefits from it, the approach of internationalisation at home must be strengthened "to ensure that the large majority of learners, the 80$90 \%$ who are not internationally mobile for either degree or credit mobility, are nonetheless able to acquire the international skills required in a globalised world." $(2013$, p. 6). To achieve this goal, the integration of foreign language into curricula and the development of digital competence is recommended. Although only the term foreign language is used in this document, English has in fact been the language chosen almost universally, thus making it a lingua franca (Bjorkman, 2008)

\section{III.2. The Spanish approach}

At the beginning of the century, the situation of EMI education in Spain was practically non-existent. Thus, in the study by Ammon and McConnell (2002), cited by Coleman (2006, p.7), in which they analyze the number of programs taught in English in European countries, none of the universities in Spain had a degree in English in the 1999-2000 academic year.

Gradually, different universities began to incorporate the teaching of subjects mainly in English and, in some cases, in other foreign languages. Such is the case of the universities in the Basque Country that in the 2010-2011 academic year already taught more than 100 subjects in a foreign language (Cenoz, 2010, p. 29). A later study that aims to take a snapshot of the level of implementation of bilingual programs in Spain (Ramos García, 2013) presents a scenario in which degrees are gradually emerging that are taught in English, although very slowly. From these results, he highlights that "the most common degrees in English are those related to Business Administration, Economics, Engineering and the like" (p. 109). An example of this trend can be seen in the study by Dafouz \& 
Smit (2016) carried out at the School of Economics and Business Administration of the Universidad Complutense de Madrid.

Parallel to the steps that have been taken in our country, we find that there is a lack of homogeneous application of the different aspects that are considered fundamental. Such is the case, for example, of the linguistic level required of the students, in each university and even in each degree from the same university, in order to be able to access a bilingual program (Halbach et al, 2013, p. 120)

In Spain, the Ministry of Education, Culture and Sport published the Strategy for the Internationalisation of Spanish Universities: 2015-2020. After a diagnosis of the situation in all the universities, a series of general and specific objectives were defined. In the diagnostic study, the low rate of training given in English and other foreign languages was already detected as a weakness of the Spanish university system (p. 20), and it was therefore recommended that the objective of including bilingual training in the degrees should be pursued (p. 32).

The Spanish universities gave a boost to this project with the publication in 2017 of the Linguistic Policy for the Internationalisation of the Spanish University System: A framework document (Bazo \& González, 2017). This document defines the courses of action aimed at guaranteeing language accreditation, language training and incentives, for the three groups that make up the university community: students, teaching staff and administration. Of all of them, we would like to highlight those referring to student training (p.17):

- Promote the teaching of courses which develop the ability to understand and express academic content (both oral and written) in a foreign language.

- Provide training in order to develop multilingual and multicultural skills with the aim of heightening awareness of language and communication in different linguistic and cultural contexts, and satisfactorily participating in mobility programmes.

- Focus on developing strategies to help solve potential communication problems and cultural differences which facilitate learning. 
- Prepare students to effectively deal with professional situations in multicultural and multilingual contexts.

\section{III.3. The linguistic policy in the Canary Islands}

Decree 168/2008, published in the Official Bulletin of the Canary Islands on August 1, 2008, regulates the procedure, requirements and evaluation criteria for the authorization of the implementation of university education leading to the obtaining of an official Degree or Master. Among the requirements, we find the knowledge of a second language, which will preferably be English, with an adequate level and in accordance with the needs that the graduates of each degree will have. This requirement is specified in the obligation to teach at least five percent of the credits in that language. In the case of four-year degrees, this percentage of teaching in a foreign language is set at 12 credits (ECTS). These credits can be taken either in subjects of the English language itself or in different subjects of the degrees, which are taught in English.

\section{OBJECTIVES: RESEARCH QUESTIONS}

Once the introduction and the institutional policy have given us an overview of the context, through the measures taken by the different institutions at European, Spanish and Canarian level, it is time to list the objectives of our study. We will define the objectives through the following research questions:

- Research question 1: How has the University of Las Palmas de Gran Canaria applied the Decree $168 / 2008$, which requires five percent of the credits to be taught in a foreign language?

- Research question 2: Can the University of Las Palmas de Gran Canaria implement English as a Medium of Instruction and respond favourably to the requirements for such teaching?

- Research question 3: What conditions must be met in order to teach the subject Learning Professional Skills for Engineers in English? 


\section{METHOD OF ANALYSIS AND RESULTS}

Since the three research questions force us to adopt different methods of analysis, we will jointly present the method of analysis and the results for each of the research questions.

\section{V.1. How has the University of Las Palmas de Gran Canaria applied the Decree $168 / 2008$ which requires five percent of the credits to be taught in a foreign language?}

Since the decree of the government of the Canary Islands can be interpreted in a flexible way, the University of Las Palmas de Gran Canaria gave the option that the five percent of teaching in English could be covered by: teaching English for Specific Purposes or by teaching in English other subjects that are part of the curriculum of each degree or master's degree.

Obviously, there are a number of degrees where the teaching of English is compulsory by its very nature. We refer to the Degree in Translation and Interpreting, Degree in Modern Languages, and Degree in Tourism. There are others in which the teaching of English is also compulsory because they are regulated by ministerial orders. Such is the case of the Degree in Primary Education and the Degree in Early Childhood Education. In the remaining degrees, one of the two following options has been consistently chosen: teaching English for Specific Purposes (ESP) or using English as a Medium of Instruction (EMI).

In the table below we present the data obtained from the university's website (https://www2.ulpgc.es/index.php?pagina=plan_estudio\&ver=inicio). In the first column, we specify the degrees that are the object of our analysis, organized by areas of knowledge (Arts and Humanities, Health Sciences, Social and Legal Sciences, Engineering and Architecture, and Science). In the second column, we detail the number of degrees that have chosen to incorporate an English for Specific Purposes (ESP) subject into their curriculum. And finally, the third column lists the degrees that teach five percent of their teaching in English (EMI). 
Table 1. The teaching of English in the Degrees of Las Palmas de Gran Canaria University

\begin{tabular}{|c|c|c|}
\hline Degrees & ESP & EMI \\
\hline Arts and Humanities & 2 & 0 \\
\hline Health Sciences & 2 & 2 \\
\hline Social and Legal Sciences & 4 & 5 \\
\hline Engineering and Architecture & 12 & 1 \\
\hline Science & 0 & 1 \\
\hline TOTAL & 20 & 9 \\
\hline
\end{tabular}

Of the data provided in the table above, there is one that we would like to highlight. A year ago, the Degree in Computer Engineering carried out a modification of its curriculum and opted to abandon the ESP model and take advantage of the EMI model. This decision has implied a change of subjects that is reflected in the following table.

Table 2. Subjects of the Degree in Computer Engineering taught in English

\begin{tabular}{|c|c|c|}
\hline Subjects & ESP & EMI \\
\hline Communication Techniques for Engineering I (6 ECTS) & $\mathrm{V}$ & \\
\hline Communication Techniques for Engineering II (6 ECTS) & $\mathrm{V}$ & \\
\hline Professional Skills for Engineers (6 ECTS) & & $\mathrm{V}$ \\
\hline Software Engineering and Management Projects (6 ECTS) & & $\mathrm{V}$ \\
\hline
\end{tabular}

\section{V.2. Can the University of Las Palmas de Gran Canaria implement English as a Medium of Instruction and respond favourably to the requirements for such teaching?}

To answer this question, we will start by defining the conditions that are considered indispensable for the teaching of a subject according to the EMI model. In the study by Morrell Moll et al. (2015) an analysis was made of the reality of EMI teaching at the University of Alicante. In this study, special attention is paid to the training of both 
teachers and students, as well as their attitudes. For this study, teacher and student surveys were used. The results of the teacher surveys reflect that most of the respondents believe that they have a $B 2$, that they are in favour of increasing the educational offer in EMI, but that they are not willing to teach their classes in English. There are two reasons for this refusal: their insufficient linguistic and methodological training (p. 2107). For their part, most of the students consider themselves to have a B1 level, but curiously enough they show a positive attitude towards the possibility of being taught in English.

Let us now look more closely at the conditions required for successful EMI teaching.

\section{V.2.1. Language level of students and teachers}

Obviously, an inadequate language level of both students and teachers is the main difficulty when implementing teaching in a foreign language (Coleman, 2006, p. 6). In order for students to successfully complete a university course in a foreign language they need to have a level of at least B2. In other words, students "are not learners of English, but speakers of it". (Bjorkman, 2008, p. 36). However, it does not seem that this level of mastery is within the reach of most students, as noted by Gómez López et al. (2014). In this study conducted in the Teacher Training College of Valencia, the level ranges from $A 2$ to $B 1$. The reasons that this study reflects are two: "The lack of reading habits in English and an insufficient development of reading strategies." (p. 155)

As for the teaching staff, it is essential that they have an adequate linguistic level in general English and the specific linguistic competence to perform in their area of knowledge (Fortanet-Gómez, 2012, p. 60). In countries where EMI is widely established, the language competence of teachers is sometimes considered to be the only variable to be taken into account. Thus, the title of the paper by Airey (2004), Can you teach it in English?, "refers to the experience of many Swedish University lecturers who have been asked this question by their head of department." (p. 105)

We commented earlier that Spanish universities agreed in Linguistic Policy for the Internationalisation of the Spanish University System (Bazo \& González, 2017), the 
courses of action aimed at guaranteeing language accreditation and requirements for teachers (p. 16):

- Recommend a CEFR level of C1 with reference to the certifications approved by the Linguistic Boards (and/or ACLES) as an advised minimum level for faculty members involved in the teaching of bilingual / multilingual courses.

- Promote the duly funded procedures so that teaching staff may certify the levels of foreign languages in which they teach.

- Promote the participation of faculty members in training programmes which will prepare them for bilingual teaching, by including such programmes in their planned, subsidised training schemes.

- Offer linguistic support to teachers prior or/and during their teaching

In the above quotation, the need for a C1 level is mentioned. To clarify what this actually means, the Council for Europe's Common European Framework of Reference for Languages (2001, p.24) details the following categories of language use:

Can understand a wide range of demanding, longer texts, and recognise implicit meaning. Can express him/herself fluently and spontaneously without much obvious searching for expressions. Can use language flexibly and effectively for social, academic and professional purposes. Can produce clear, well-structured, detailed text on complex subjects, showing controlled use of organisational patterns, connectors and cohesive devices.

However, this set of capacities reflected in level $\mathrm{C} 1$ is in some cases not considered sufficient. This is the opinion, for example, of the Delft University of Technology. This university evaluated its teaching staff to determine their level of English, in the $2006 / 2007$ academic year (Klaasgen \& Bos, 2010). Specifically, the final purpose was to determine if their staff had a C1 level assessed through IELT (International English Language Testing System). The results showed that $55 \%$ had a $\mathrm{C} 1$, but when assessing this result, it was considered necessary for the teaching staff to have a C2, for the following reasons (p. 75): 
If we are to prepare our local students for global citizenship we have to offer them the opportunity to listen to lecturers with a C2 level of English and provide the opportunity to acquire the languages at an acceptable level themselves.

\section{V.2.2. Pedagogical training of teachers}

Although the didactic training of teachers to teach in a foreign language is a fundamental aspect, we find that it is being implemented in an uneven way. Therefore, it seems necessary to develop a model which takes into account different methodological approaches implemented in other contexts, to focus on the different types of language required in the classroom and to pay special attention to the suggestions and recommendations of studies carried out through systematic observation (Martín del Pozo, M.A., 2013, p. 214).

The importance of this specific pedagogical training, besides being necessary, is valued very positively by university teachers (Fernández, 2015). However, this same study points out the need to increase the training offer, since the teaching staff, when asked, considers that:

The number of courses is insufficient and the training provided has not improved their teaching methodology. Moreover, it is the opinion of lecturers that the training received does not qualify them to teach through English. (p. 103)

The Spanish universities also established the courses of action aimed at training EMI teachers (Bazo and González, 2017, p. 18). One of the proposed courses of action is "Offer initial and continued training, both of a linguistic and methodological nature, for those who teach in a foreign language."

\section{V.2.3. Current situation in this university}

Let us now see what the reality of this university is in the two aspects considered fundamental: the linguistic level of the teaching staff and students, and the pedagogical training of the teaching staff.

It is not an easy task to know the exact linguistic level of the teaching staff. From 2017 onwards, language accreditation has been included in the university admission scale, 
but the vast majority of the teaching staff were recruited before that date, so the data we have available have been provided on a voluntary basis. Of the 1648 teachers, we have data from 249 who are distributed by level as follows.

Table 3. Teacher accreditation by level

\begin{tabular}{|c|c|}
\hline Common European Framework English Level & Total \\
\hline C2 & 3 \\
\hline C1 & 91 \\
\hline B2 & 107 \\
\hline B1 & 49 \\
\hline All levels & 235 \\
\hline
\end{tabular}

From the above data, we must subtract from the total of 91 teachers with level C1, 37 teachers who are from the area of English Philology. In summary, we have 57 teachers with at least a C1 in English, which allows this university to have a sufficient number of instructors who could start teaching their subjects in English.

As for the student accreditation data, we find a situation similar to that detected in the teaching staff. We refer to the fact that students are not obliged to provide the university with their language certificates. It is basically the students interested in obtaining Erasmus scholarships who have provided this documentation to the university. Below we present the data referring to the Undergraduate and Master's students.

Table 4. Student language accreditation by level

\begin{tabular}{|c|c|}
\hline Common European Framework English Level & Total \\
\hline C2 & 24 \\
\hline C1 & 304 \\
\hline B2 & 547 \\
\hline B1 & 878 \\
\hline
\end{tabular}




\begin{tabular}{|l|c|}
\hline All levels & 1753 \\
\hline
\end{tabular}

We can see from the general data that we have almost 900 students with at least a B2 level, which raises the possibility of starting to teach a series of subjects in English. But if we take into account that the total number of students in Bachelor and Master degrees is 18,000 , the options for teaching in the EMI format are obviously very limited.

Let us now look at the didactic training received by the teaching staff in the last two years. The Teacher Staff Training Plan focuses on four general training dimensions: 1. Teaching, tutorial action and innovation; 2. Research; 3. Management and quality, and 4. Internationalization. Within the actions focused on internationalization, the following language and pedagogical training courses have been offered in the last two years. The number of times each course has been offered is specified in parentheses.

Table 5. Training courses and teachers positively evaluated

\begin{tabular}{|l|c|}
\hline \multicolumn{1}{|c|}{ Language and pedagogical courses (2017-2019) } & Teachers \\
\hline Communication skills development and preparation for B2 accreditation (3) & 29 \\
\hline English for Teaching (C1) (2) & 20 \\
\hline Development and improvement of communication skills in English B2+ (1) & 7 \\
\hline Teaching in English. Reading and Listening for academic purposes (1) & 8 \\
\hline Teaching in English. Speaking and Writing for academic purposes (1) & 2 \\
\hline
\end{tabular}

Despite the fact that the number of teachers who register for each course is approximately 20 , it can be seen in table 5 that the final results of those who pass the courses are very low. These results are clearly insufficient when compared to the total number of teachers (1648). 


\section{V.2.4. What conditions must be met in order to teach the subject Learning Professional Skills for Engineers in English?}

Since in research question number 2 , it became clear that this university does not have a sufficient number of faculty members and students to opt for teaching based on the EMI model in the degrees, we must discard the EMI option for teaching the subject in question. In view of the difficulties caused by the linguistic level of the students, the option of Integrating Content and Language in Higher Education (ICLHE) is beginning to take hold (Wilkinson, 2004; Wilkinson \& Zegers, 2008; Costa, 2012; Dafouz \& Smit, 2012, 2014; Doiz et al, 2013). It is, in short, an adaptation to the university context of the CLIL (Content and Integrated Language Learning) format widely used in non-university centres.

To implement ICLHE it is necessary to design a teaching project for each subject in which both the academic and the linguistic objectives are specified (Pavón \& Gaustad, 2013, p. 85)

That is to say, we must set ourselves the linguistic objective of helping our students reach the B2 level. To clarify what this actually means, the Council of Europe's Common European Framework of Reference for Languages details the following capacities of language use:

Can understand the main ideas of complex text on both concrete and abstract topics, including technical discussions in his/her field of specialization. Can interact with a degree of fluency and spontaneity that makes regular interaction with native speakers quite possible without strain for either party. Can produce clear, detailed text on a wide range of subjects and explain a viewpoint on a topical issue giving the advantages and disadvantages of various options. (2001, p. 24)

In the learning of any university subject, it is presupposed that, in addition to the specific contents of the subject, there should also be linguistic training at the level of the discourse that is proper to that subject. The syllabus must incorporate multiple opportunities for students to become familiar with texts specific to the subject, while at 
the same time asking them to produce both oral and written documents of similar characteristics. However, in most cases these aspects are not usually specified in the curricular content, being part of the hidden curriculum. Moreover, we sometimes find that teachers are not very receptive when it comes to incorporating linguistic objectives. This opinion is summarised in the following sentence "I don't teach language", title of Airey's article (2012)

Finally, it is particularly important to check that the application of these linguistic objectives is reflected in observable learning outcomes (Aguilar \& Muñoz, 2014). The academic objectives of each subject should not be affected by its teaching in a foreign language. What is of vital importance is to take into account that in order to achieve them we must facilitate, especially, the oral and written comprehension of the students. In addition to offering models of oral and written expression that enable students to express themselves adequately on the subject matter in question.

From the previous paragraph two aspects can be deduced that we consider very relevant. As our students have B1 language level it is not enough to help them achieve a B2 level in order for them to achieve their academic goals. It will be necessary to help them understand texts, both oral and written, that will obviously be of a higher language level than what Vigotsky defined as "zone of proximal development". To achieve this level of comprehension we will need to include the following strategies:

- The teacher should incorporate in his or her oral discourse, interactive adjustments that will facilitate the overall comprehension: repetitions, comprehension checks, and non-linguistic aspects (Penate \& Boylan, 2005)

- To facilitate the understanding of written or audio-visual texts it will be necessary to use compensation strategies such as: skimming, scanning, predicting, guessing the meaning of unknown words, referents, use of the layout, etc. (Huntley \& Peñate, 2003)

To facilitate the production of oral and written texts that are related to the subject of the course, we will have to guide the students and for this purpose the scaffolding technique is especially relevant. 


\section{DISCUSSION OF RESULTS}

The first research question already provides us with a piece of information that we consider relevant. Only nine of the 29 degrees analysed use EMI, despite the fact that Decree 168/2008 of the Canary Islands Government in its article 4 establishes as a requirement the teaching of at least five percent of the credits in English. The spirit underlying this decree was to teach "in" English and not the teaching "of" English. However, shortcomings that are exposed through our second research question, led to the solution of teaching English for Specific Purposes.

We have 57 teachers with at least a C1 in English, which could allow us to consider the possibility of using the EMI method in some degrees or in different subjects of a degree. The data on the linguistic level of the students could also reinforce this point of view. However, the problem arises when we see that the distribution of the 900 students with at least a B2 level in English, is diluted among the almost 18,000 students of this university. Moreover, the concentration of students with a B2 level is precisely in the two master's degrees that are taught in English. In other words, the percentage of students with a B2 level for each of the four courses that make up each degree is very low.

\section{CONCLUSIONS}

The two previous paragraphs present us with a situation in which we have a considerable number of teachers without the necessary language training and a number of students who have not yet reached the B2 level. In other words, we must choose the option of Integrating Content and Language in Higher Education (ICLHE). And to do so, at least three fundamental aspects must be taken into account:

- It is necessary to have teachers trained at least at a linguistic level of (C1)

- Teachers must have the didactic training that will allow them to incorporate the necessary strategic skills to help students overcome the difficulty involved in 
understanding and expressing themselves at a higher linguistic level than they possess.

- To incorporate specific objectives of the subject and linguistic objectives in the teaching projects. Language objectives inspired by the competencies of the seven skills of the Common European Framework of Reference for Languages specified for level B2.

\section{REFERENCES}

Aguilar, M. \& Muñoz, C. (2014). The effect of proficiency on CLIL benefits in Engineering students in Spain. International Journal of Applied Linguistcs, 24(1), 1-18.

Airey, J. (2004). Can you teach it in English? Aspects of the language choice debate in Swedish higher education. In R. Wilkinson (Ed.), Integrating content and language. Meeting the challenge of a multilingual higher education (pp. 97-108). Maastricht: Maastricht University.

Airey, J. (2012). "I don't teach language". The linguistic attitudes of physics lectures in Sweden. AILA Review, 25, 64-79.

Airey, J. \& Linder, C. (2006). Language and the experience of learning university physics in Sweden. European Journal of Physics, 27, 553-560.

Airey, J. \& Linder, C. (2008). Bilingual scientific literacy? The use of English in Swedish University Science courses. Nordic Journal of English Studies, 7(3), 145-161.

Airey, J., Lauridsen, K.M., Räsänen, A., Salö, L. \& Schwach, V. (2015). The expansion of English-medium instruction in the Nordic countries. Can top-down university language policies encourage bottom-up disciplinary literacy goals? Higher Education, 73, 561-576. DOI 10.1007/s10734-015-9950-2

Ammon, U. \& McConnell, G. (2002). English as an academic language in Europe: A survey of its use in teaching. Bern: Peter Lang. 
Bazo, P. \& González, D. (coordinators) (2017). Linguistic Policy for the Internationalisation of the Spanish University System: A framework document. CRUE Universidades Españolas.

Berg, E.C., Hult, F.M. \& King, K.A. (2001). Shaping the climate for language shift? English in Sweden's elite domains. World Englishes, 20(3), 305-319.

Bjorkman, B. (2001). 'So where we are?' Spoken lingua franca English at a technical university in Sweden. English Today, 24(2), 35-41.

Cenoz, J. (2010). El inglés como lengua de instrucción en la Universidad: nuevas tecnologías y multimodalidad. Ikastaria. Cuadernos de Educación, 17, 25-38.

Coleman, J.A. (2006). English-medium teaching in European higher education. Language Teaching, 39(1), 1-14.

Costa, F. (2012). Focus on form in ICLHE lectures in Italy. Evidence from English-medium science lectures by native speakers of Italian. AILA Review, 25, 30-47.

Council of Europe (2001). Common European Framework of Reference for Languages: Learning, teaching, assessment. Cambridge: Cambridge University Press.

Dafouz, E. \& Smit, U. (2012). Integrating content and language in higher education. An introduction to English-medium policies, conceptual issues and research practices across Europe. AlLA Review, 25, 1-12.

Dafouz, E. \& Smit, U. (2016). Towards a dynamic conceptual framework for EnglishMedium education in multilingual university settings. Applied Linguistics, 37(3), 397-415.

Doiz, A., Lasagabaster, D. \& Sierra, J.M. (2011). Internationalisation, multilingualism and English-medium instruction. World Englishes, 30(3), 345-359.

Doiz A., Lasagabaster, D. \& Sierra, J.M. (2013). English-medium Instruction at Universities: Global Changes. Bristol: Multilingual Matters.

European Commission (2013). European Higher Education in the World. 
<https://ec.europa.eu/transparency/regdoc/rep/1/2013/EN/1-2013-499-EN-F11.Pdf $>[26 / 04 / 2020]$.

Fernández-Costales, A. \& González-Riaño, X.A. (2015). Teacher satisfaction concerning the implementation of bilingual programmes in s Spanish university. Porta Linguarum, 23, 93-108.

Fortanet-Gómez, I. (2012). Academics' beliefs about language use and proficiency in Spanish multilingual higher education. AlLA Review, 25, 48-63.

Gómez López, A., Solaz Portolés, J.J., Sanjosé López, V. (2014). Competencia en lengua inglesa de estudiantes universitarios españoles en el contexto del EEES: nivel de dominio lingüístico, estrategias metacognitivas y hábitos lectores. Revista de Educación, 363, 154-183.

Halbach, A., Lázaro Lafuente, A. \& Pérez Guerra, J. (2013). La lengua inglesa en la nueva universidad española del EEES. Revista de Educación, 362, 105-132.

Huntley, S. \& Peñate, M (2003). Specific reading at an advanced level: linguistic or strategic competence? IBÉRICA - Revista de la Asociación Europea de Lenguas para Fines Específicos, 5, 87-100

Klaassen, R.G. \& Bos, M. (2010). English language screening for scientific staff at Delft University of Technology. Hermes - Journal of Language and Communication Studies, 45, 61-75.

Martín del Pozo, M.A. (2013). Formación del profesorado universitario para la docencia en inglés. Revista de Docencia Universitaria, 11(3), 197-218.

Ministerio de Educación, Cultura y Deportes (2015). Estrategia para la Internacionalización de las Universidades Españolas: 2015-2020. Madrid: Secretaría General de Universidades.

Morell Moll, T., Alesón Carbonell, M., Belda Medina, J.R., Bell Kruse, D. Escabias Lloret, P., Finestrat Martínez, I., Palazón Speckenz, M., Stoll-Dougall, P., Whitehead Cambra, D. \& Martínez-Espinosa, R.M. (2015). La enseñanza de contenidos en 
inglés en el proceso de internacionalización de la Universidad de Alicante. In J.D. Álvarez Teruel, M. T. Tortosa Ybañez \& N. Pellin Buades (Eds.), Investigación y Propuestas Innovadoras de Redes UA para la Mejora Docente (pp. 2097-2114). Alicante: Universidad de Alicante

Norwegian Ministry of Education and Research (2007). European Higher Education in a Global Setting. A Strategy for the External Dimension of the Bologna Process. <http://www.ehea.info/media.ehea.info/file/EHEA_in_a_Global_Context/24/2/S trategy_plus_possible_actions_597242.pdf > [26/04/2020].

Pavón Vázquez, V. \& Gaustad, M. (2013). Designing bilingual programmes for higher education in Spain: organisational, curricular and methodological decisions. International CLIL Research Journal, 2(1), 82-94.

Penate, M. \& Boylan, G. (2005). The effect of interactional adjustments on the overall comprehension of spoken texts: a case study. JALT Journal, 2, 187-207.

Ramos García, A.M. (2013). Higher Education Bilingual Programmes in Spain. Porta Linguarum, 19, 101-111.

Wilkinson, R. (2004). Integrating Content and Language. Meeting the Challenge of a Multilingual Higher Education. Maastricht: Maastricht University.

Wilkinson, R. \& Zegers, V. (2008). Realizing content and language integration in higher education. Maastricht: Maastricht University.

Received: 6 September 2021 